\title{
O letramento e o sociocognitivismo: elementos para uma teoria da resistência
}

\author{
Atilio Butturi ${ }^{1}$
}

\section{Resumo}

Este texto pretende, a partir de uma abordagem discursiva, fazer uma discussão das teorias de Letramento a partir das concepções da psicologia sociocognitiva, na tentativa de entender uma possibilidade de resistência comum a ambos os discursos. Para tanto, parte-se inicialmente de uma leitura de alguns textos de Vygotski e, finalmente, relaciona-se a complexização de categorias utilizadas pelo russo com a empresa de algumas das vertentes do Letramento, sobretudo aqueles ditos ideológicos, que se voltam para problemáticas como identidade e ética e, assim, descrever a construção de um discurso de resistência microfísica nas teorias de ensino e aprendizagem de língua materna em sua modalidade escrita.

Palavras-chave: Psicologia sociocognitiva. Letramento. Resistência.

\begin{abstract}
This paper intends, from a discursive approach, to make a reading of theories of literacy from the conceptions of social-cognitive psychology in an attempt to understand the possibility of resistance common to both speeches. To do so, it starts initially from a discursive reading of some texts of Vygotsky and, finally, relates to cumbersome category undertaken by the Russian company with a few strands of Literacy, mainly those sayings ideological, who wish to observe problems such as identity and ethics, and therefore undertake the construction of a discourse of resistance microphysics theories of teaching and learning of language in its written modality.
\end{abstract}

Keywords: Sociocognitive psychology. Literacy. Resistance.

\section{Introdução}

Alvo de algum debate acerca das posições marxistas e destas em relação à constituição do pensamento, o discurso de Vygotsky tem se prestado à elaboração de diversas metodologias de ensino de língua materna, sobretudo daquelas formuladas a partir do conceito de Letramento - caro aos documentos oficiais no Brasil e vedete de diversas políticas atuais.

Dada essa importância, este artigo pretende discutir estes discursos - a psicologia sociocognitiva e o letramento - segundo a ordem de uma reelaboração das relações de poder

\footnotetext{
${ }^{1}$ Doutorando-UFSC-Prof-UFFS-RS. Mestre em Lingüística pela Universidade Federal de Santa Catarina, Brasil(2008). Professor Assistente I da Universidade Federal da Fronteira Sul , Brasil. a_butri@yahoo.com.b
} 
que ofereceriam, no seu bojo, a possibilidade de ultrapassamento de determinações históricosociais via multiplicação de esferas e circulação do poder. É visando essa microfísica, como rede complexa de poderes e resistências, que se efetuará uma leitura-tradução-modificação dos discursos.

Para tanto, este artigo está organizado da seguinte maneira: primeiramente, apresentase apontamentos acerca do pensamento de Vygotsky; em seguida, percorre-se algumas das empreitadas de configuração do que seja "letramento"; finalmente, reelabora-se os questionamentos do letramento - sobretudo Street(2003) - à luz das teorias foucaultianas da microfísica do poder e da micro-história.

\section{Vygotski ${ }^{2}$ e o marxismo envergonhado}

Numa edição de A formação social da mente (VIGOTSKI, 1996), um prefácio elaborado por Michel Cole e Sylvia Scribner oferece algumas problematizações axiais que percorrem o discurso de Vygotsky: a tentativa de associar uma teoria cognitiva com a neurologia (baseando-se em Fechner e Sechenov); uma teoria sobre o funcionamento das funções mentais ditas superiores em que o elemento cultural torna complexa a relação entre mente e exterioridade; e, o que aqui me parece profícuo ${ }^{3}$, a vinculação da teoria culturalizante a um modelo de estruturação social marxiano.

A leitura dos textos do russo se pautará, portanto, na injunção de descrever este discurso, na hipótese de que nele resida justamente uma possibilidade - ainda que não devidamente desenvolvida - de ultrapassar o determinismo que sonda tanto a teoria da mente quanto o pensamento marxiano.

Começo justamente pelos textos desse $A$ formação... Os capítulos discutidos em sala foram Internalização das funções psicológicas superiores (4), Interação entre aprendizado e desenvolvimento (6) e A pré-história da linguagem escrita (8). Do primeiro deles, escolho os sentidos de “funções superiores” como objeto a deslindar.

Nesse capítulo (4), Vygotski retoma uma discussão do primeiro capítulo do livro, a saber, que há uma relação entre o instrumento pensado por Engels e a linguagem como instrumento do pensamento. É mister não perder Engels de vista, já que o psicólogo retoma um leitmotiv marxiano clássico: a transformação da natureza realizada pelo homem cria a 
cultura e, nesse processo, o homem se constitui como sujeito. Dito de outro modo, transformar a natureza acaba por transformar a natureza do homem e tal só é possível via instrumento - o meio pelo qual o homem age na exterioridade, transformando- a.

Em Vygotski, o processo é redefinido com vistas à interioridade, na tentativa de explicar o mental - peixe na água, Vygotski não se equipara a um Quine ou a um Rorty no seu colocar em xeque uma teoria da mente. Assim, seu discurso pretende que haja um papel de instrumento na linguagem humana, que permite um salto qualitativo (ecos hegelianos incontestes) entre uma operação imatura prática e imediata e uma outra, complexa e mediada, "uma forma fundamentalmente nova de comportamento" (VIGOTSKI, 1996, p.33).

Indo adiante no mesmo livro, no terceiro capítulo, Vygotski (1996, p.61) afirma que há a transformação, via instrumento, para operações superiores da mente:

\begin{abstract}
Podem-se distinguir, dentro de um processo geral de desenvolvimento, duas linhas qualitativamente diferentes de desenvolvimento, diferindo quanto à sua origem: de um lado, os processos elementares, que são de origem biológica; de outro, as funções psicológicas superiores, de origem sócio-cultural. A história do comportamento da criança nasce do entrelaçamento dessas duas linhas.
\end{abstract}

Sublinho: há um processo de transformação marxista-hegeliano, cuja teleologia inaugura uma ordem superior. Ordem superior, nesse caso, diz respeito à diferenciação entre o elementar primeiro e o psicológico segundo, sendo este segundo mediado e possível pelo aparecimento da linguagem, pelo "uso do signo" que destaca o desenvolvimento humano das necessidades naturais.

Ademais, é fundamental não perder de vista o caráter de crítica realizado pela própria teoria marxiana ao conceito de natureza, que fica patente na discussão das ideologias: a função da ideologia seria a de mascaramento da ordem social, responsável pela legitimação da estrutura pela criação de uma superestrutura cultural. No interior desse discurso, aquilo que se entende por natureza deve ser constantemente revisto, pois traz no bojo não só a dominação como a impossibilidade de transformação (MARX; ENGELS, 1989).

Tomando essa dificuldade em relação ao natural, vou ao capítulo 4, já citado e lido em aula. Vygotsky defende que há analogia entre signo e instrumento porque ambos têm a “função mediadora” (VYGOTSKY, 2000, p. 71, grifos do autor). Para explicar mediação, é a Hegel e Marx que recorre o psicólogo, diferenciando então o signo do instrumento via funcionalidade: 


\begin{abstract}
A função do instrumento é servir como um condutor da influência humana sobre o objeto da atividade; ele é orientado externamente; deve necessariamente levar a mudanças nos objetos. Constitui um meio pelo qual a atividade humana externa é dirigida para o controle e domínio da natureza. O signo, por outro lado, não modifica em nada objeto da operação psicológica. Constitui um meio da atividade interna dirigido para o controle do próprio indivíduo; o signo é orientado internamente.
\end{abstract}

Nos parágrafos seguintes, Vygotsky explica a filogênese do pensamento superior fazendo a analogia indiscutível com a transformação da natureza marxiana: a linguagem humana permite um controle do pensamento do mesmo modo pelo qual o instrumento permite o domínio da natureza. A distinção entre signo e instrumento de trabalho, pois, seria da ordem do interno e do externo, na medida em que o signo opera saltos qualitativos no interior do sujeito. Não obstante, também o signo participa da estrutura histórico-social que permite aos modos de produção criarem suas superestruturas, o que cria um moto-contínuo de estruturações.

Volto à teoria e pergunto: como se daria esse salto qualitativo? Pela internalização socialmente realizada de operações, pela qual os processos interpessoais se tornam intrapessoais, por um ultrapassamento daquilo que aparece como natureza, nos termos do próprio Vygotsky (2000). No entanto, uma ressalva importante: qualquer uma das atividades é marcada por características tipicamente ideológicas (se nos detivermos no marxismo solicitado na página 72), visto que as atividades internalizadas serão, por excelência, “socialmente enraizadas e historicamente desenvolvidas [...]” (VYGOTSKY, 2000, p. 76).

Tal leitura inicial e marxiana da teoria de Vygotski seria responsável, ao que parece, por certo discurso que defende, no russo, um papel de destaque para a apropriação cultural e por uma suplantação do biológico (a mente, o pensamento, o primário) por uma linguagem sempre-já mediando qualquer relação entre pensamento e exterioridade. No limite marxiano dessa interpretação, haveria um imperativo de determinação - ou ao menos condicionamento - do pensamento “individual” pelo sócio-histórico.

A fim de problematizar essa posição - que me parece sempre “sedutora” pela assunção do marxismo nesse início do século XX - seria possível ponderar que haveria uma tripartição do discurso entre uma filogênese biologizante, uma sociogênese culturalmente englobante e uma microgênese subjetivamente e microfisicamente diferenciadora e, mais do que isso, responsável pela resistência diante das demais esferas. ${ }^{3} \mathrm{O}$ que existiria no discurso 
vygotskiano, dessa perspectiva, seria uma não resolvida complexização das esferas, que não permitiria pensar em uma rigidez estruturante.

Pretendo, pois, argüir a letra vygotskiana sob a égide de uma positividade pósestrutural: se há no russo uma microfísica subjetivante (ao menos no limite), trato de buscar suas marcas a fim de relacioná-las á teorias contemporâneas de resistência para, finalmente, discutir tal resistência nos chamados Novos Estudos de Letramento (STREET, 2003).

Então, ao percorrer os textos de Vygotski, gostaria de investigar tal empresa de superação marxiana (sob a ótica subjetivamente determinista) partindo de algumas questõeschave: a relação com o cognitivismo, que não parece definitivamente esclarecida quando se trata de funções superiores; a importância dada nos textos à história dos sujeitos diante da linguagem e dos simbolismos sociais; o papel da aprendizagem no desenvolvimento.

Inicio com o que apresentei acima como o cognitivismo em Vygotski. Em Pensamento e palavra, podemos ler já no início que as relações entre pensamento e palavra não são prédadas, são “um produto e não uma premissa da formação do homem” (VYGOSTKI, 2001, p. 394). Nessa esteira é que se poderá afirmar que não há vínculo primário entre pensamento e linguagem e, por conseguinte, é necessário que ambos tenham uma identidade e uma diferenciação.

O grande questionamento do discurso do psicólogo, porém, se dá diretamente em relação ao que chama de "falha metodológica” (VYGOTSKY, 2002, p. 396), que consiste em tratar analiticamente pensamento e linguagem. Hegelianamente - outra vez - a escolha metodológica recai na tentativa de binarismo entre parte e todo: a alteridade encontrada entre pensamento e linguagem deve ser pensada em termos de Totalidade e desmembramento. Nesse caso, ao invés do Espírito hegeliano, o que se teria era o significado da palavra, interstício e unificação, num só tempo, do mental e do sígnico. A “tese fundante” é assim descrita:

O significado da palavra só é um fenômeno de pensamento na medida em que o
pensamento está relacionado à palavra e nela materializado, e vice-versa: é um
fenômeno de discurso apenas na medida em que o discurso está vinculado ao
pensamento e focalizado por sua luz. É um fenômeno do pensamento discursivo ou
da palavra consciente, é a unidade da palavra com o pensamento. (VYGOTSKY,
2001, p. 398)

A empresa de Vygotski consiste em tornar complexa a relação entre uma teoria da mente e uma teoria social de formação da mente. Para tanto, diferente do que postularia uma 
semântica marxista - do tipo da de Schaff -, uma análise do discurso - semelhante à francesa - ou da teoria bakhtiniana de um simbolismo ideológico primevo da mente, o psicólogo russo vai insistir no amálgama estrutural significado da palavra, a fim de, no mesmo golpe, garantir a alteridade entre pensamento cognitivo e palavra social e a unidade incorruptível entre a natureza e a cultura.

No que se refere à unidade, é necessário não perder de vista o imperativo marxiano da empreitada: não se pode alcançar uma habilidade superior do pensamento destacada do mundo superestrutural, bem como não se é praticável sair do reino da necessidade sem uma apropriação mediada no interior do mundo da cultura - devidamente permeado dos imperativos ligados aos modos de produção econômicos.

Nos termos de Vygotski, o que se tem é um processo funcional em fases, no qual pensamento se direciona à palavra. Entretanto, Vygotsky (2001, p. 412) nega as teorias especulares, para as quais o pensamento seria representado por palavras: “A linguagem não serve como expressão de um pensamento pronto. Ao transformar-se em linguagem, o pensamento se reestrutura e se modifica. O pensamento não se expressa mas se realiza na palavra.” Caminhar para o desenvolvimento de funções superiores, então, é percorrer um caminho de introjeção de um semântico exterior e de caráter social, portanto modificável e de caráter processual.

Outrossim, há uma espécie de promessa de subjetividade: se há um precedente ao menos enunciável, se há um mental salvaguardado - ainda que incipiente e a ser suplantado , esse mental teria como competência fazer deslocamentos de duas ordens, a natural imperativa e a individual transformadora. No último caso, é sempre um vislumbre de resistência legado ao sujeito que se pode entrever - aqui é bom lembrar as leituras de Morin acerca de um biológico sempre-já desestruturado ou das teorias caóides que se multiplicam nas ciências exatas/naturais.

Um conceito importante faz pensar, ainda, nesse caráter de resistência dado ao mental, o de linguagem interior. O postulado seria de que “[...] a linguagem interior é uma formação particular por sua natureza psicológica, uma modalidade específica de linguagem dotada de particularidades absolutamente específicas [...]” (VYGOTSKY, 2001, p. 425). 
O que caracterizaria o entendimento de Vygotski de uma linguagem interior seria justamente sua precedência em relação à linguagem social exterior e, mais importante, sua permanência como uma linguagem para si, autotélica.

Criticando a postura de Piaget em relação à linguagem egocêntrica, o russo afirma que esta é a chave do entendimento de uma linguagem interior. Enquanto em Piaget o desenvolvimento implicaria um abandono da linguagem egocêntrica infantil, em Vygotski é a linguagem egocêntrica uma linguagem interior ainda socializada (porque externalizada em palavras) a ser transformada, posteriormente, numa estrutura primordial ao pensamento "superior".

Assim, o declínio das manifestações externas não poderiam mais ser vistos, como em Piaget, como desenvolvimento e abandono da fala interior. Pelo contrário, o psicólogo russo aposta no fim da vocalização e da socialização como características fundantes de funcionamento específico do uso da linguagem, baseado numa predicatividade pura, numa fragmentação funcional e numa preponderância do semântico - em detrimento do fonético/material da fala egocêntrica.

Tal desenvolvimento da fala egocêntrica, chamado então de linguagem interior, teria uma "função intelectual específica” (VYGOTSKY, 2001, p. 462), qual seja, ser a linguagem do pensamento. Nesse caso, complementa-se a tese asseverando um “idiotismo” limítrofe e uma incompreensão social basilar. Não obstante, a liberdade subjetiva é novamente discutida via semântica: ainda que autotélica, a linguagem interior se elabora via sentidos móveis e inscritos socialmente: “A linguagem interior é o momento dinâmico, instável, fluido, que se insinua entre os pólos extremos melhor enformados e estáveis do nosso estudo do pensamento verbal: entre a palavra e o pensamento.” (VYGOTSKY, 2001, p. 474).

Novamente, a defesa de uma “refração" interior da linguagem só poderá ser pensada dentro de um discurso dito complexo, estruturado no vértice não devidamente resolvido entre pensamento e palavra. A aposta na subjetividade, todavia, surge em Vygotski também quando este se refere à necessidade de assunção de uma história prévia da aprendizagem, anterior não só à educação formal mas à própria maturação cognitiva defendida por teorias como as de Piaget.

Tomemos esse aspecto como o segundo a discutir, na modalidade da importância dada nos textos à história dos sujeitos diante da linguagem e dos simbolismos sociais. Um dos 
textos debatidos em aula é bastante claro em relação à história do desenvolvimento infantil, Estudo do desenvolvimento dos conceitos científicos na infância. Além deste, certamente a implicação entre fala egocêntrica e linguagem interior - citada acima - pode ser elencada nessa assunção dos diferentes históricos defendida por Vygotski, assim como a problematização da aprendizagem, a ser descrita na sequência.

Detenho-me em Estudo do desenvolvimento... no intuito de materializar um discurso que, portanto, é mola-mestra da teoria. Vigotski (2001) inicia o capítulo descrevendo dois tipos de conceitos, espontâneos e científicos. Para o autor, o desenvolvimento dos conceitos científicos guardaria a chave da história do desenvolvimento mental, mas nem se dariam de forma absoluta (seriam parte de um processo) e nem seriam um oposto radical dos conceitos espontâneos.

A partir daí, o russo aponta as teorias existentes: uma, que acredita na assimilação dos conceitos pela criança em idade escolar e prescinde da história do desenvolvimento destes; outra, cuja origem é Piaget, que não difere conhecimentos científicos dos demais conhecimentos, sendo que estes dependeriam sempre da maturação cognitiva.

O que chama atenção na discussão acerca do discurso de Piaget é que Vigotski (2001, p. 257) o descreve como uma espécie de teoria do corte, ao gosto estruturalista pelas cesuras, “[...]como uma repressão gradual e constante de uma formas por outras. [...]” , pela extinção dos conceitos espontâneos e a delimitação de um pensamento superior formado por conceitos típicos da idade adulta.

Se para o russo esse discurso de contraposição redunda em extinção, sua problematização exige três tomadas de distância: há um elo qualitativo entre espontâneo e científico; a ligação entre espontâneo e não-espontâneo é por vezes fluida; há, por conseguinte, um vínculo necessário entre desenvolvimento e aprendizagem.

Nessa esteira de valorização da história prévia dos sujeitos - certamente pensada a partir da relação já enunciada entre linguagem e pensamento via significados - recorro a um trecho em que o autor destaca a importância das reflexões no ensino de línguas:

A apreensão do sistema de conhecimentos científicos pressupõe um tecido conceitual já amplamente elaborado e desenvolvido por meio da atividade espontânea do pensamento infantil. Como ocorre na língua materna, a assimilação de uma nova língua não passa por um novo tratamento do mundo material nem pela repetição de um processo de desenvolvimento já percorrido uma vez, mas por outro 
sistema de linguagem (sic) anteriormente apreendido e situado entre a linguagem a ser reassimilada e o mundo dos objetos. (VIGOTSKI, 2001, p. 269).

Atente-se: a linguagem é reassimilada na medida em que é estruturante de qualquer linguagem segunda. Nesse caso, ao operar numa nova linguagem, constroem-se outros objetos sem perder de vista essa espécie de solo inicial que é o conhecimento espontâneo. Ademais, esse conhecimento espontâneo também está delineado num interstício que envolve, por um lado, a filogênese cognitiva, a sociogênese semântico-ideológica e uma microgênese a ser desvelada como possibilidade, já que resultante da teia complexa intentada pela teoria.

Finalmente, esse sustentáculo de complexidade é garantido pelo aparecimento de um discurso de aprendizagem que se nega a pensar o desenvolvimento (maturação) como único responsável pela formação do pensamento superior - o que é devidamente descrito no capítulo 6 de A formação social da mente.

Inicialmente, três teorias são apresentadas por Vygotsky (2000): a piagetiana, que postula uma precedência do desenvolvimento sobre a aprendizagem; as behavioristas, para as quais aprendizado é igual a desenvolvimento; a terceira, gestaltista, que tentaria produzir uma solução mediadora entre as duas primeiras. A teoria gestaltista, para Vygotsky, seria a responsável por ter transformado a importância dada ao aprendizado e, portanto, por uma mudança de postura diante do pedagógico.

Vygotsky (2000) aponta sua discordância diante dos três grupos de teorias, considerando que todo conhecimento tem uma história prévia e, isto posto, elabora o desenvolvimento segundo níveis de desenvolvimento: real, correspondente aos conhecimentos já completados e que prescindem de ajuda de outrem; potencial, formado pelo conjunto de conhecimentos que a criança atinge com auxílio de adultos; proximal, que seria a diferença entre os dois primeiros. Nas palavras de Vygotsky (2000, p. 112), a zona de desenvolvimento proximal:

[...] é a distância entre o nível de desenvolvimento real, que se costuma determinar através da solução independente de problemas, e o nível de desenvolvimento potencial, determinado através da solução de problemas sob a orientação de um adulto ou em colaboração com companheiros mais capazes.

O fundamental para esse texto é considerar a zona desenvolvimento proximal sob a égide da manutenção da complexidade. Isso porque Vygotski aposta no papel da educação e da socialização como parte necessária do desenvolvimento do pensamento. Destarte, não apenas desenvolvimento é uma categoria diferente da aprendizagem como, de forma 
semelhante ao que postulava para linguagem e pensamento, o elo que une tais categorias não pode ser observado por uma teoria analítica simples, mas apenas por uma que dê conta de uma relação sempre-já processual: "Nossa hipótese estabelece a unidade mas não a identidade entre os processos de aprendizado e os processos de desenvolvimento interno.[...]” (VYGOTSKY, 2000, p. 118).

Retomo o questionamento princeps: em qual medida o discurso tripartido (filogênese, sociogênese e microgênese) no qual insiste Vygotski pode ser mantido e, além disso, como se conforma a uma teoria marxiana, por excelência anti-humanista e determinista - não se perca de vista a sobredeterminação econômica em última instância.

Fundamentalmente, no horizonte da teoria russa do início do século estava a necessidade de alinhamento à doutrina do regime - e o estalinismo tornará isso radical. Nessa prática específica, o psicólogo poderia ser lido sob a égide de dois discursos: ou bem se toma um marxismo com tentativas de se equiparar a teorias subjetivistas - a psicanálise, por excelência, era uma teoria burguesa e necessitava de um contraponto do regime - ou bem se estabelece uma cisão não realizada por uma condição de produção determinante, qual seja, o autoritarismo do regime.

De todo modo - e aqui sequer se aventa a incipiência das teorias do mental - é certo que Vygotski não faz a transformação da teoria marxiana, uma vez que aposta numa constituição social da consciência a partir da importância que dá ao pensamento de segunda ordem, ao pensamento maduro mediado por signos sociais.

No entanto, essa sociogênese é constantemente colocada em xeque - ainda que nesse caso sem a mesma consistência teórica - por conceitos que evocam uma subjetividade constitutiva ou um imperativo biológico incontornável. Em ambos, menos que uma estruturação definitiva, o que se tem são aportes de complexidade que amiúde surgem no discurso e que exigem uma leitura revigorada do marxismo, no que tange à resistência.

É como uma espécie de arauto de novos tempos do marxismo (uma espécie de marxismo envergonhado que nos é caro contemporaneamente) que Vygotski nos fala com um dos herdeiros de uma virtude comum, vinda do pensamento materialista dialético e retomada em Espectros de Marx, por Jacques Derrida: a virtude da revolta. Uma herança da qual ainda nós somos herdeiros, não da perspectiva de uma escolha, mas como uma precedência fundamental, como um discurso que nos constitui. O “espírito do marxismo”, para Derrida 
(1994), é um espectro que não ontologia definida, mas reage diante de todas as denegações (modernas e pós-modernas) na forma de um messianismo não metafísico: "talvez uma certa experiência emancipatória”.

Para observar o discurso do letramento e sua vinculação com o construtivismo à Vygotski, gostaria de trazer à tona algumas reflexões que encaminhariam uma assunção do tipo de letramento defendido por Street (2003), considerado pelo próprio autor como ideológico mas, numa quase-contradição (não se pode ser pós-estrutural e ao mesmo tempo metanarrativo), localista e complexo.

\section{Sobre letramento e emancipação}

\subsection{Revolução, emancipação e resistência}

Se o pensamento marxiano clássico pautava-se numa idéia de poder e resistência circunscritos, esses foram discutidos na segunda metade do século XX por uma vertente que aqui chamarei, para fins didáticos, de pós-estrutural. A característica básica destes discursos é uma incredulidade geral diante dos metarrelatos, pautada numa negação das explicações e determinações última e num papel ativo do sujeito, não obstante limitado a intervenções locais.

Nesse texto, elaboro por fim uma relação entre teoria do poder pós-estrutural, complexização vygostskiana e teoria de letramento. O objetivo é o de refutar as teses de verticalização do poder e impossiblidade de transformação que vieram à tona no seminário, por meio de um outro discurso niilista, localista e jamais metacrítico - típico do discurso conhecido como "pós-estrutural”.

Primeiramente, a fim de avançar numa caracterização desse pós-estrutural, parto inicialmente daquilo que Foucault inscreveu como genealogia - uma palavra de ordem desses discursos. Genealogia se refere à multiplicidade das discussões iniciadas na década de setenta do século XX que têm por característica a “insurreição dos saberes dominados" (FOUCAULT, 1999a, p. 170) na tentativa de deslindar um modo de entendimento das relações entre uma tudo o quanto foi expulso como resíduo na construção dos discursos da cientificidade conforme os conhecemos. Trata-se, pois, de interrogar a positividade dos 
saberes a sua exterioridade, sua relação necessária e direta com estratégias micro e macrofísicas pelas quais o poder é exercido.

Para tanto, o projeto genealógico foucaultiano estará pautado no entendimento de uma positividade intrínseca ao poder (poder-saber), esse mesmo reduzido à instância de prática e negado em qualquer possibilidade ontológica: o poder, na genealogia, não poderá se circunscrever aos mecanismos de repressão estatal negativa, pois procede de relações capilares sempre em circulação. Como ubiqüidade, o poder é a rede na qual aos aparelhos de controle estatais corresponderá sempre um nível de autonomia da periferia. Como positividade, o poder extrapolará o nível da lei e o da violência (o modelo jurídico), justamente porque ao ser exercido é capaz de criação de discursos e mesmo de individualidades - desde Surveiller et punir, de 1975, Foucault nos conta da capacidade de aprimoramento e disciplinarização de que o poder é capaz diante da docilidade dos homens.

Na empresa de descrever seu objeto, em Soberania e disciplina, Foucault (1999b) reelabora cinco "precauções metodológicas" acerca do poder que incidem sobre a genealogia: captar o poder em suas ramificações, na capilaridade que foge das leis e das instituições, penetrando-as transversalmente; estudar as estratégias do poder investidas em práticas reais e efetivas em sua relação com sujeitos e objetos; analisar o poder como algo não localizável, que funciona e se exerce em rede; partir de uma análise infinitesimal, cujo produto é a descrença na dominação global e, por conseguinte, atentar para a possibilidade de mecanismos microscópios existirem e proliferarem; levar em consideração a existência de acumulações do saber na forma de instituições.

Contrário ao que chamava de "hipótese repressiva” do poder, cujo epítome era justamente a teoria marxista do poder soberano, centralizado e estruturante do social, o que se vê aqui é uma negação da opção vertical e uma crença na horizontalidade de um poder que, por excelência, circula e pode ser exercido por qualquer um daqueles que estejam envolvidos em suas relações. Poder, então, exige que se pense em resistências e que essas não sejam legadas a revoluções de grande escala mas a eventos microscópicos nos quais os sujeitos extrapolam os limites rígidos das leis férias e inauguram séries de normalizações devidamente desestruturadas, diferenciais e efêmeras.

É dessa capacidade de resistência - não negativa mas constitutiva do poder - que se retomaria o discurso vygotskiano. Ultrapassando o cognitivismo explicativo ou certa idealidade subjetivista - o russo cita Vossler e Humboldt sem quaisquer pudores -, a 
alternativa de reler Vygotski e sua não determinação filogenética ou sociogenética seria correspondente, guardadas as devidas proporções, às teorias microfísicas de resistência.

Nessa esteira, o caráter ativo da subjetividade poderia também ser reelaborado via desenvolvimentos contemporâneos: Morin (1996) e Certeau (1994).

No debate acerca das resistências, Morin (1996) elege a subjetividade como locus privilegiado. Para tanto, rediscute a peremptoriedade das conclusões marxiana da autoprodução do homem na produção do social considerando cultura e linguagem como mecanismos de objetivação da individualidade e sua resultante identidade socialmente definida.

Inversamente proporcional a essa determinação social, haveria um substrato egocentrado de nível biológico, que estaria em constante articulação e dicotomia com os imperativos da sociogênese, fazendo a contraposição entre os sistemas. Desse embate, o que se teria como produto é uma desordem suportável por qualquer dos organismos - máquina, corpo ou instituição social. Segundo Morin (1996, p.276):

\footnotetext{
As sociedades humanas toleram uma grande porção de desordem; um aspecto dessa desordem é o que chamamos liberdade. Podemos então utilizar a desordem como um elemento necessário nos processos de criação e invenção, pois toda invenção e toda criação se apresentam inevitavelmente como um desvio e um erro com respeito ao sistema previamente estabelecido.
}

Menos que características de um sujeito cartesiano, a liberdade aqui é estruturalmente diferença, pela qual a adaptação de todo organismo é possível. A complexidade sugerida seria compósito de dois movimentos: negação de qualquer onisciência; assunção de espaços frágeis de liberdade e necessidade de utilização destes positivamente, pela construção de "metapontos de vista limitados”(MORIN, 1996) que jamais descartam a inserção prévia no cultural.

Na esteira foucaultiana, ainda Certeau (1994) aponta o urbano e o contemporâneo como espaços de resistência localistas, subjetivas e microscópicas diante dos agenciamentos impostos cotidianamente, numa identificação-desindentificação permanente entre aquilo que um poder centralizador oferece e um deslocamento-distanciamento realizado por operações ínfimas dos sujeitos.

Para uma teoria de leitura e escrita, é imprescindível que se pense em termos de resistência local e intersticial, suplantando portanto uma teoria da revolução. 


\subsection{Letramento, localismo e resistência}

O debate sobre o acesso à cultura escrita, no Brasil, ganhou destaque na década de noventa com o trabalho pioneiro de Magda Soares e Angela Kleiman. Categorizadas de formas distintas (TINOCO, 2008), à primeira coube um papel de introdutora, enquanto à segunda a reputação de trazer à tona o modelo dito ideológico de letramento.

Seguindo os passos das autoras - e diferenciando-se destes - os estudos brasileiros do letramento permanecem utilizando a alcunha ideológico, forjada em 1983 por Brian Street, para dar conta de questões que ultrapassam tanto o limite tecnológico e maquínico das teorias de alfabetização, quanto a redução de grupos homogêneos a que se deveria "letrar”, partindo de pesquisas etnográficas cujos resultados têm mostrado a dificuldade sempre-já de reduzir os sujeitos e seus grupos ao modelo oferecido pelo cientista.

Além de Street, também Barton surge com destaque no discurso nacional de letramento: por um lado, porque evoca diretamente Paulo Freire como um precursor dos letramentos ideológicos; por outro, porque oferece uma metáfora interessante para se refletir acerca do acesso ao mundo da escrita, qual seja, a ecologia: as ações com a linguagem escrita estão sempre-já incluídas num meio ambiente específico, agindo portanto sobre ele e o influenciando, no mesmo movimento em que são influenciadas e circunscritas pela rede em que se dão (BARTON, 1994a).

Nesse caso, Barton (1994b) apontará o imperativo de se pensar ações com linguagem escrita de maneira situada, sendo que cada evento de letramento estará ancorado numa prática social de letramento que extrapola os limites imediatos e está inscrita numa materialidade social e histórica.

Em Street (2003) e Barton (1994a, 1994b) ainda é notória a preocupação em não reduzir o letramento às práticas escolarizadas ou formais. O que chamam de "evento de letramento” ocorreria em práticas diversas em que houvesse mediação por textos escritos.

Ao que parece, é na diversidade procurada e muitas vezes refratária ao mundo disciplinar do pedagógico que residiria o diferencial da hipótese de Street (2003):

Em vez de privilegiar as práticas específicas de letramento que sejam familiares em sua própria cultura, hoje em dia os pesquisadores preferem abster-se do julgamento sobre o que consiste o letramento entre as populações com as quais estejam 
trabalhando, até que lhe seja possível entender o que significa para as próprias populações. [...] (STREET, 2003, p. 6)

Inversão de um primado: ao invés de uma educação redentora e centralizada, o que Street (2003) esclarece é que há um modelo de letramento que não comunga do discurso emancipador total via cultura escolar herdeira de uma concepção Iluminista e teleológica, e prefere então um ativismo que se á em âmbito local. Se, pois, um fracasso permanece sondando as teorias de aprendizado de leitura e escrita, tal poderia ser visto de modo positivo, com a valorização da alteridade e sua axiologia própria diante dos eventos e das práticas da escrita.

Nessa esteira, Soares (2003), Gee (2004) dão conta do fracasso da escola no processo de formação de leitores-escritores ${ }^{4}$. No caso brasileiro, Soares (2003) entende o hiato criado pela escola na perspectiva da "transposição didática”: a escola seleciona práticas específicas e apenas estas são contempladas e legitimadas como práticas de letramento.

Nota vygotskiana: os discursos do letramento reelaboram a preocupação do russo em relação aos históricos subjetivos e sociais de aprendizagem. Além disso, no caso dos letramentos ecológicos e ideológicos, há uma preocupação com a complexização, desta feita destituída de um efeito cognitivo imediato e voltada sobremaneira ao entendimento de redes sociais microfísicas.

Explico-me: a defesa realizada pelos New Literacy Studies vai ao encontro direto de certa resistência possível, que é o mote com o qual Street (2003, p. 12-13) rebate a acusação de romantizar o local:

[...] A abordagem etnográfica não envolve um compromisso apenas com o status quo: ao contrário, os pesquisadores mostram-se comprometidos com a transformação social [...] hoje em dia a boa prática em educação exige que os facilitadores expandam aquilo que os aprendizes trazem para a sala de aula, ouvindo e não apenas transmitindo [...] Da mesma maneira, a boa prática política exige que os desenvolvedores escutem de onde as pessoas vêm, expandindo os pontos fortes locais, sem simplesmente imaginar que fosse possível trabalhar sem eles.

Já em 1969, na Arqueologia do saber, Michel Foucault postulava uma passagem do obstáculo à prática. No caso do letramento, o que Street propõe é ampliar o escopo do letramento, entendendo para tanto que nem apenas este ocorre formalmente e verticalizado, como também que as próprias práticas locais tem a força de resistir, são fontes de um poder que circula e é capaz de denegar aquilo que institucionalmente fora decidido de antemão 
como a cultura - e aqui é fácil lembrar das “narrativas de resistência” que muitos de nós confessamos encontrar em nossa trajetória de ensino.

Esse discurso localista e emancipador sugere que repensemos certo pessimismo com as metanarrativas: se a escola não permite que se cumpram suas mais alvissareiras promessas de revolução, estaria reservado à assunção de outras práticas menos valorizadas socialmente a promessa de soluções fora do discurso do Mesmo.

\section{Considerações finais}

Esse artigo intentou uma leitura particular do vértice letramento-sociocognitivismo, rastreando em Vygotski - essa vedete de qualquer pedagogia "sócio" - alguns elementos que propusessem uma ponte entre uma teoria típica da psicologia do início do século XX e do marxismo e um ultrapassamento de ordem teórica com vistas à complexidade ativa das vertentes pós-estruturalistas.

Dessa perspectiva, ainda que haja uma leitura imediata de pessimismo por uma revolução perdida, a tentativa foi de reelaborar os discursos do letramento de forma positiva: um entendimento menos revolucionário e mais localista, o que parece mais emancipatório, afinal, nos tempos atuais.

\footnotetext{
${ }^{1}$ Usarei as grafias diferentes de Vygotski, conforme as edições citadas.

${ }^{2}$ A empresa desse texto é uma leitura circunscrita e não exaustiva, um quase-afeto diante da teoria.

${ }^{3}$ Há, aqui, um ponto que surge merecedor de destaque: também a teoria que se vale de Bakhtin pretende que esse tenha criado o conceito de ideologias do cotidiano para rebater uma estruturação "em última instância". No caso de Bakhtin, haveria uma resistência (refração) por meio de relações menos institucionalizadas que acabariam por resistir às ideologias constituídas. Certamente, não se trata de reunir teorias e, como muitas vezes se vê nas discussões - até aquelas entabuladas no seminário - nem de reduzir o debate da escrita aos gêneros bakhtinianos. Entretanto, é bom não perder de vista que também a teoria de gêneros pretende muitas vezes "contornar" o nó marxiano que envolve o pensador russo - e aqui caberia marcas o plural russos.

${ }^{4}$ Algo que já estava presente no texto de Ines Signorini, Letramento e (In)flexibilidade comunicativa, publicado no livro clássico de Kleiman.
}

\section{Referências}

BARTON, D. Talking about literacy. In: . Literacy: an introduction to the ecology of written language. Cambridge, USA: Brackwell, 1994a. p. 10-30. 
The social bases of literacy. In:

. Literacy: an introduction to the ecology of written language. Cambridge, USA: Brackwell, 1994b. p. 33-51.

CERTEAU, Michel de. A invenção do cotidiano: artes de fazer. Petrópolis, RJ: Vozes, 1994.

DERRIDA, J. Conjurar - o marxismo. In: . Espectros de Marx: o Estado da dívida, o trabalho do luto e a nova Internacional. Rio de Janeiro: Relume-Dumará, 1994. p. 73-105.

FOUCAULT, M. Genealogia e poder. In: Microfísica do poder. 11 . ed. Rio de Janeiro: Graal, 1999a. p. 167- 177.

. Soberania e disciplina. In: . Microfísica do poder. 11. ed. Rio de Janeiro: Graal, 1999a. p. 179- 191.

MARX, K. ENGELS, F. A ideologia alemã. Teses sobre Feuerbach. São Paulo: Martins Fontes, 1989.

MORIN, E. Epistemologia da complexidade. In: SCHNITMAN, D. F. (Org.). Novos paradigmas, cultura e subjetividade. Porto Alegre: Artes Médicas, 1996.

SOARES, M. Letramento e escolarização. In: RIBEIRO, V. M. (Org.). Letramento no Brasil. São Paulo: Global, 2003. p. 83-114.

STREET, B. Abordagens alternativas ao letramento e desenvolvimento. 2003. Disponível em: http://telecongresso.sesi.

$<$ org.br/templates/header/index.php?language=pt\&modo=bibliotec a\&act=categoria\&cdcategoria=22>. Acesso em: 10 nov. 2009.

TINOCO, G. A. Mundos de letramento de professores em formação no agreste rio-grandense. In: OLIVEIRA, M. do S.; KLEIMAN, A. Letramentos múltiplos. Natal: UDUFRN, 2008. p. 63-92.

VIGOTSKI, L. S. O estudo do desenvolvimento dos conceitos científicos. In: . A construção do pensamento e da linguagem. São Paulo: M. Fontes, 2001. p. 242-394.

A formação social da mente: o desenvolvimento dos processos psicológicos superiores. 5. ed. São Paulo: M. Fontes, 1996. Internalização das funções psicológicas superiores. In: A formação social da mente. 6. ed. São Paulo: M. Fontes, 2000. p. 69-76.

. Interação entre aprendizado e desenvolvimento. In: A formação social da mente.

6. ed. São Paulo: M. Fontes, 2000. p. 103-120.

Pensamento e palavra. In: A construção do pensamento e da linguagem. São

Paulo: M. Fontes, 2001. p. 395-496. 